\title{
Estimating the quantum requirements for plant growth and related electricity demand for LED lighting systems
}

\author{
Marc Schmierer $^{1}\left[\right.$ ] Holger Brueck ${ }^{2} \cdot$ Folkard Asch $^{1} \cdot$ Joachim Sauerborn ${ }^{1}$
}

Received: 11 February 2020 / Revised: 29 December 2020 / Accepted: 15 January 2021 / Published online: 18 February 2021

(c) The Author(s) 2021

\begin{abstract}
Indoor plant production systems with artificial lighting are considered an emerging technology contributing to biomass-based value webs. The viability of this concept greatly relies on the energy requirements (ER, Watt) for lighting. We estimated the ER for plant growth by calculating the conversion efficiency of electricity to light of solid-state light-emitting diodes (LED) and the quantum requirements for plant growth of a fictional plant stand producing $2500 \mathrm{~g}$ of dry weight per $\mathrm{m}^{2}$ of ground during 100 days, representing a high productivity benchmark of field crops. The quantum output $\left(\mu \mathrm{mol} \mathrm{s} \mathrm{W}^{-1}\right)$ of eight LEDs of different colours varied between 0.78 for green and 2.54 for deep red. Uncertainty in the $\mathrm{H}^{+}$demand for ATP synthesis during photosynthesis, the relative portion of photorespiration and the fraction of light intercepted by plant canopies $\left(f_{\text {abs }}\right)$ were considered in a pessimistic (PA) and optimistic (OA) approach of calculation of ER. Cumulative ER were 606 and $265 \mathrm{kWh} \mathrm{m}^{-2}$ for the PA and OA scenarios. The energy conversion efficiencies in the PA and OA scenarios were 2.07 and $4.72 \%$. Estimates of energy savings by suppressing photorespiration and increasing $\mathrm{f}_{\text {abs }}$ vary between 24 and $38 \%$. The peak daily ER were 9.44 and $4.14 \mathrm{kWh}$ in the PA and OA scenarios. Results are discussed in the context of the design of lighting in indoor plant production systems and commercial greenhouses where natural fluctuation in solar radiation could be balanced by dimmable LED panels.
\end{abstract}

Keywords LED efficiency $\cdot$ Radiation use efficiency $\cdot$ Indoor plant production

\section{Introduction}

The 8.5 bn people living on earth in 2030 as projected with the medium fertility variant by the United Nations (2019) will aggravate the threat of food shortage. Climate change (Lobell et al. 2008), regional shortfall of freshwater availability (Falkenmark et al. 1997), and the foreseeable decline in fossil oil (OECD/IEA 2011) and high-grade rock phosphate resources (Cordell et al. 2009; Gilbert 2009) will both amplify food insecurity and challenge presently existing concepts of food production. Rice, wheat, maize, and barley form the backbone of the global food processing value chain, and the Food and Agriculture Organization of the

Marc Schmierer

marc.schmierer@uni-hohenheim.de

1 Hans-Ruthenberg-Institute, Institute of Agricultural Sciences in the Tropics, University of Hohenheim, 70599 Stuttgart, Germany

2 Research Centre Hanninghof, Yara International, Dülmen, Germany
United Nations (FAO) estimates that annual world cereal production must increase by about $60 \%$ (Alexandratos and Bruinsma 2003) to meet the projected demand in 2050. This requires extension of arable land area (including land conversion), intensification of production by an increased and more efficient use of resources, such as nutrients and water (Tilman et al. 2011), and substantial improvements in harvest, transport, and storage technologies (Kitinoja et al. 2011). However, such an increase in production has to be considered in the context of the socio-economic framework conditions (Cohen 1997) and the external costs (e.g., greenhouse gas emissions, loss of biodiversity) related to these measures (Walsh 1991; Balmford et al. 2002).

Particularly external costs of food production (principally transport, energy demand of storage and food losses of vegetables) stimulated concepts of plant cultivation in contained indoor systems, where vegetable or crop plants are grown in artificial indoor systems comprising components for artificial lighting, nutrient supply and environmental control (temperature, $\mathrm{CO}_{2}$ concentration and air humidity). Research on indoor growth systems were initiated in the frame of 
space flight missions (Zabel et al. 2016) and are, with less sophisticated control over environmental factors, going to be established in commercial factories focusing on high-value crops such as vegetables (Shamshiri et al. 2018). A similar approach of plant cultivation is followed in proposed vertical farming concepts (Despommier 2011; Beacham et al. 2019) and some authors have specifically mentioned rice as a target crop for indoor staple food production (Germer et al. 2011; Song et al. 2018). These concepts seek to illustrate the feasibility of partially substituting food production on arable land. A central feature of such visionary indoor plant production systems is the evaluation of related energy demand. Studies on energy demand have to consider energy expenditure for temperature and humidity control and lighting systems with the latter being the preponderant item of energy balance sheets for indoor plant factories.

Since the commercial release of the first red LEDs in 1968, the development of solid-state LEDs has progressed rapidly. Projections indicate that, due to energy savings, LEDs may displace all traditional lamps for general illumination within the next few decades (Haitz and Tsao 2011). As compared with the successful implementation of solid-state LEDs in technical applications (e.g., indicator lights, room and street lighting, screens and flashlights), LED technology starts to be widely used in greenhouses (Shamshiri et al. 2018). While low radiant efficiency and the effects of light quality on growth and photo-morphogenesis of plants due to the few available wavelengths restricted the use of first generation LEDs in greenhouses (Bula et al. 1991), current LED lighting systems for plant growth match high-pressure sodium (HPS) lamps in terms of electrical efficiency and light quality. HPS lamps are gas-discharge lamps that use excited sodium to emit light of a relative broad spectrum. In growth environments which exclusively rely on artificial lighting, LEDs could be a prime technology, especially since light intensity can be adjusted to the plants' specific demand while the thermal load for the plants is lower than with HPS lamps (Folta et al. 2005; Massa et al. 2008; Morrow 2008).

Information about the plants' energy demand for growth is essential for future design of LED-based lighting systems. We present calculations of the quantum requirements (moles of plant usable light quanta needed to produce a certain amount of biomass) for plant growth and combine this with related electric energy demand for indoor environments equipped with LED lighting. By using a standard data set of plant growth parameters, our approach allows for an approximate estimation of temporal dynamics of energy demand of LED lighting fields in indoor-growth environments.

\section{Materials and methods}

\subsection{Estimating cumulative electric energy requirements}

In the following, we present equations which enable the reader to calculate the energy demand for their crop and growth environment of interest.

Equations 1-4 summarize classical approaches of crop growth physiology and can be applied to any crop of interest, from greenhouse vegetables to broad acre crops. Equation 3 can be used to quantify daily crop growth rates by fitting curve parameters to the crop's expected yield and growth duration. Equations 2 and 4 are useful to adjust energy content of crop organs during the growth period. For further details, readers are encouraged to consult the cited crop growth publications.

Equations 5-7 specify how crop energy demand is converted to LED performance. With advances in LED development, technical specifications will necessarily change, but the basic approach will stay as outlined.

The cumulative electric power requirement [ER, Watt hour ( $\mathrm{m}^{2}$ ground $\left.)^{-1}\right]$ is here defined as the ratio of the quantum requirements $\left[\mathrm{QR}\right.$, mol quanta $\left.\left(\mathrm{m}^{2} \text { ground }\right)^{-1}\right]$ for the built-up of dry mass over time and the conversion efficiency of electricity to light $\left(\mathrm{CO}_{\mathrm{Eff}}\right.$, mol quanta $\left.\mathrm{Watt}^{-1}\right)$ and can be calculated by Eq. 1 .

$\mathrm{ER}=\mathrm{QR} / \mathrm{CO}_{\mathrm{Eff}}$

\subsection{Estimating quantum requirements}

QR was calculated according to Eq. 2:

$$
\begin{aligned}
\mathrm{QR}= & \left(\mathrm{dY} \times \mathrm{GLU}_{\text {reqG. }}+\mathrm{Y} \times \mathrm{GLU}_{\text {reqM }}\right) \\
& \times 0.0 \overline{3} \times(\mathrm{a}+\mathrm{b} \Phi) \times\left(1+1-\mathrm{f}_{\text {abs }}\right),
\end{aligned}
$$

where construction costs for daily dry weight formation [dY, g DW ( $\mathrm{m}^{2}$ ground $)^{-1}$ day $\left.^{-1}\right]$ are expressed in glucose requirements $\left[\mathrm{GLU}_{\text {reqG. }}, \mathrm{g}\right.$ glucose $\left.(\mathrm{g} \mathrm{DW})^{-1}\right]$. Carbon costs for maintenance respiration $\left[\mathrm{GLU}_{\mathrm{reqM}}, \mathrm{g}\right.$ glucose $(\mathrm{g} \mathrm{DW})^{-1}$ ] are related to standing biomass $\left[\mathrm{Y}, \mathrm{g} \mathrm{DW}\left(\mathrm{m}^{2} \text { ground }\right)^{-1}\right]$ and $0.0 \overline{3}$ is a conversion factor from $\mathrm{g}$ glucose to mol C considering the molar stoichiometry of carbon and glucose $(72 / 180=0.4)$ and the conversion from $\mathrm{g} \mathrm{C}$ to mol C $(0.4 / 12=0.0 \overline{3})$. The conversion from glucose to $\mathrm{mol} \mathrm{C}$ is necessary for calculating daily QR for carboxylation which is defined by the term $(a+b \Phi)$ and depends on the relative rate of oxygenation to carboxylation $(\Phi)$. The term $f_{\text {abs }}$ is the portion of incident light which is absorbed and used in photosynthesis by the plant canopy. E.g., with a value of $f_{\text {abs }}$ 
of 0.8 , the term $1+1-\mathrm{f}_{\mathrm{abs}}$ is 1.2 , indicating that $\mathrm{QR}$ is $20 \%$ higher than if it were in a situation of complete absorption of quanta by the plant surface.

The equation is conceptually very similar to the radiation use efficiency (RUE) approach of Amthor (2010), where detailed explanations of energy demand calculations can be found.

QR was calculated for a fictional highly-productive plant

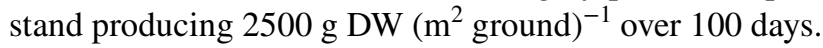

We assumed for our calculations that $500 \mathrm{~g}$ of DW are invested in the root system (relative root allocation factor of 0.2 ) and $50 \%$ of the aboveground biomass is invested in final grain yield. Detailed dry mass allocation coefficients for crops and vegetables are reported in Haenel et al. (2020). This hypothetical crop would realize a grain yield of $1000 \mathrm{~g}$ $\left(\mathrm{m}^{2} \text { ground) }\right)^{-1}$. This yield level (equivalent to 10 tons of grain per hectare) represents a high productivity benchmark of field crops such as rice and wheat. For indoor plant production, and particularly vegetables, similarly high growth rates are realistic and the estimated QR presented in this paper are, therefore, representative for a highly productive plant species in general. QR varies over time as growth rate and chemical composition of plants change. In order to consider this, a fictional growth dynamic of a plant stand was calculated with the symmetric expolinear function suggested by Goudriaan, cited in Yin et al. (2003):

$d Y=\frac{c_{\mathrm{m}}}{r_{\mathrm{m}}} \ln \frac{1+e^{r_{\mathrm{m}}\left(t-t_{\mathrm{o}}\right)}}{1+e^{r_{\mathrm{m}}\left(t-t_{\mathrm{o}}-w_{\max } / c_{\mathrm{m}}\right)}}$.

Values used were 40 for the maximum growth rate $\mathrm{c}_{\mathrm{m}}$, 0.2 for the maximum relative growth rate in the expolinear phase $r_{m}, 20$ for the time when linear growth begins, $t_{\mathrm{o}}$, and 2500 for final weight $\mathrm{w}_{\max }$. Of the aforementioned values the maximum growth rate of $40 \mathrm{~g} \mathrm{~m}^{-2}$ per day is a high but reasonable value (Lambers and Poorter 1992) and 0.2 and 20 were selected to create a reasonable shape of the growth curve. Values of target yield and maximum growth rate for different environments can be easily adjusted for other plant species. Carbon costs for growth $\left(\mathrm{GLU}_{\mathrm{ReqG}}\right)$ were calculated from information about ash-free heat of combustion $\left(\Delta \mathrm{H}_{\mathrm{C}}\right.$, $\mathrm{J} \mathrm{kJ}^{-1}$ ) of grain (18.5), stem (17.5) and $\operatorname{root}(16.5)$ (Amthor 2010) according to Griffin (1994):

$$
\begin{aligned}
\mathrm{GLU}_{\mathrm{ReqG}}= & {\left[\left(0.06968 \mathrm{DH}_{\mathrm{C}}-0.065\right)(1-\mathrm{AC})\right.} \\
& \left.+7.5\left(\mathrm{k}_{\mathrm{N}} \times \mathrm{Nc} / 14.0067\right)\right]\left(1 / \mathrm{E}_{\mathrm{g}}\right),
\end{aligned}
$$

with ash content $\left(\mathrm{AC}, \mathrm{g} \mathrm{g}^{-1}\right)$ of grain $(0.015)$ and straw (0.044) taken from Jørgensen et al. (2007). The straw data were assumed to represent those of leaf, stem and root tissue. $\mathrm{N}$ content $\left(\mathrm{g} \mathrm{g}^{-1}\right)$, in a simplified approach, was assumed to be constant over time with values of 0.04 (leaf) and 0.02 (root, stem, grain). A $\mathrm{k}_{\mathrm{N}}$ value (considering costs of $\mathrm{N}$
Table 1 Coefficients for calculating the quantum requirements (a, b), the ratio of oxygenation to carboxylation $(\Phi)$ and the fraction of light absorbed by leaves $\left(f_{a b s}\right)$ in the pessimistic (PA) and optimistic (OA) approach

\begin{tabular}{llrll}
\hline Scenario & $\mathrm{a}$ & $\mathrm{b}$ & $\Phi$ & $\mathrm{f}_{\mathrm{abs}}$ \\
& \multicolumn{2}{l}{ Dimensionless } & & \\
\hline PA & 12 & 13.5 & 0.28 & 0.70 \\
OA & 9 & 10.5 & 0.05 & 0.95 \\
\hline
\end{tabular}

assimilation) of 5 (sole nitrate- $\mathrm{N}$ supply) and $\mathrm{E}_{\mathrm{g}}=0.87$ were used (see Griffin 1994). The assumed GLU ReqG. were 1.287, 1.219 , and 1.149 g glucose (g DW) ${ }^{-1}$ for grain, stem and root tissue, respectively. Experimental estimates of maintenance respiration rates vary from 15 to $50 \mathrm{mg} \mathrm{Glu} \mathrm{g}^{-1} \mathrm{DW}$ day $^{-1}$ (Loomis and Amthor 1999). We took a value of $30 \mathrm{mg}$ Glu $\mathrm{g}^{-1}$ DW.

Uncertainty in the calculations of daily QR arises from factors which can be technically manipulated such as the environmental $\mathrm{CO}_{2}$ concentration (variable rate of oxygenation to carboxylation, $\Phi)$ as well as the fraction of light absorbed by the plant canopy $\left(\mathrm{f}_{\mathrm{abs}}\right)$. Additionally, uncertainty in $\mathrm{QR}$ exists as 'true' quantum costs for production of energy and reducing equivalents is not clear. This is considered by a pessimistic (PA) and optimistic (OA) approach (see Table 1 and text below).

Carbon demand for growth and maintenance is equivalent to the required rate of carboxylation, $\mathrm{V}_{\mathrm{C}}$ per unit ground area, which can be expressed as $(a+b \Phi)$. This term quantifies the required production rates of energy (ATP) and reducing equivalents $[\mathrm{NAD}(\mathrm{P}) \mathrm{H}]$ sustaining the rates of carboxylation and oxygenation according to von Caemmerer and Farquhar (1981). The required rate of ATP consumption is $(3+3.5 \Phi) \mathrm{V}_{\mathrm{C}}$. We assumed that either three or four $\mathrm{H}^{+}$are required for the synthesis of 1 ATP (Sacksteder et al. 2000). Consequently, rates of proton production were $(9+10.5 \Phi) \mathrm{V}_{\mathrm{C}}$ or $(12+13.5 \Phi) \mathrm{V}_{\mathrm{C}}$ in the optimistic and pessimistic approaches, respectively (Table 1). Relative rates of photorespiration $(\Phi)$ were assumed to be 0.28 or 0.05 under ambient or high atmospheric $\mathrm{CO}_{2}$ concentrations (Lambers and Poorter 1992), respectively with the ambient $\mathrm{CO}_{2}$ concentration used in the PA scenario. The fraction of quanta which are absorbed by leaves $\left(f_{a b s}\right)$ depends on reflective properties of the leaf surface and the absorption efficiency which depends on pigment density (Evans and Poorter 2001). An additional source of inefficient quanta absorption is the portion of ground coverage and reflective properties of the ground surface. In the OA scenario we assume a fraction of absorbed quanta of 0.95 , which would represent an optimized indoor design with permanent complete ground cover and use of highly reflective material of the growth chamber inner surfaces. A value of 0.70 was assumed in the PA scenario. This 
value is representative for field crops which do not reach full canopy cover (Lambers and Poorter 1992). In indoor systems such low values could be realized if floor or wall materials are not highly reflective.

Conversion efficiency of electricity to biomass $(\varepsilon ; \mathrm{J} / \mathrm{kJ})$ was calculated by dividing the cumulated energy of plant biomass by the electricity demand for LED lighting. An energy content of $18.1 \mathrm{~kJ}(\mathrm{~g} \mathrm{DW})^{-1}$ (Jørgensen et al. 2007) was assumed for plant biomass.

\subsection{Calculation of conversion efficiency of electricity to light of LEDs}

LED suppliers usually specify the efficacy of illuminants in terms of the photometric luminous flux. For the calculation of photosynthetically active quanta ( $\mu \mathrm{mol}$ PPFD $\mathrm{m}^{-2}$ $\mathrm{s}^{-1}$ ), we first converted the photometric luminous flux to the physical luminous flux. The relationship between photometric and physical luminous flux is given by:

$\Phi_{\mathrm{v}}=\mathrm{K}_{\mathrm{m}} \int_{380 n m}^{780 n m} \frac{d e^{(\lambda)}}{d \lambda} \times V(\lambda) d \lambda$,

where $\Phi_{\mathrm{v}}$ is the photometric luminous flux in Watt, $\Phi_{\mathrm{e}}$ is the physical luminous flux in Lumen for a specific wavelength $\lambda$ and $V(\lambda)$ is the luminous efficiency function of the human eye (photopic) in Lumen per Watt with its highest value $\mathrm{K}_{\mathrm{m}}$ of $683.002 \mathrm{1} / \mathrm{W}$ at a wavelength of $555 \mathrm{~nm}$.

For the conversion, we determined the relative spectral power distribution $S(\lambda)$ of LED spectra reported in specific datasheets of Osram (Osram Opto Semiconductors GmbH \& Co., Regensburg, Germany). The graph of the spectral distribution from the datasheet was converted to a monochromatic image and the numerical values of the distribution were estimated by self-written software with a resolution of $1 \mathrm{~nm}$. The total physical luminous flux of the LED was then calculated according to Eq. 6:

$\Phi_{\mathrm{e}}=\frac{\Phi_{\mathrm{v}}}{\sum_{380 n m}^{780 n m} K_{m} \times V(\lambda) \times S(\lambda)}$,

with $\phi_{\mathrm{v}}$ given in the specific datasheet. Subsequently, $\phi_{\mathrm{e}}(\lambda)$ was calculated by multiplying the relative spectral power distribution $S(\lambda)$ for each wavelength with the formerly calculated total physical luminous flux of the illuminant.

For the calculation of photosynthetically active quanta, the photonic energy per wavelength was calculated as:

$E=\phi \times \frac{h c}{\lambda}$,

where $\mathrm{h}$ is the Planck constant and $\mathrm{c}$ is the speed of light. The number of quanta per wavelength was calculated by dividing the numerical values of the power distribution for each wavelength by the dedicated photonic energy. Finally, the number of photosynthetically active quanta was calculated by integrating all photons between 400 and $700 \mathrm{~nm}$.

It should be noted that the brightness values given in the datasheets are typical values measured under the specified test conditions. For detailed information about test conditions and measuring inaccuracy, information provided in the datasheets should be considered. Due to production related fluctuations in certain LED parameters such as peak wavelength and optical flux, LEDs from a particular model are usually classified into different wavelength and brightness groups. The values presented in this paper usually refer to LEDs that are specified as 'typical' in the data sheets.

The software for the estimation of the relative spectral power distribution from the LED datasheets was written in $\mathrm{C}++$. For image analysis, we used the Qimage class provided by the Qt framework version 4.7.4 (http://qt-proje ct.org/). Binaries and source code are available from the authors on request. Information about four LED types and a combination from deep red and deep blue LEDs and for HPS (SON-T $400 \mathrm{~W}$, PHILIPS, The Netherlands) are summarized in Table 1. The quantum output for LEDs was calculated for different colours and varied between 0.83 for true green and 2.64 for deep red. Calculations are presented for HPS lamps, cool white LEDs, and a combination of deep red and blue LEDs with a red:blue photon ratio of 5:1. Distribution of electrical energy between deep red and blue LEDs was 4.29:1. For the calculation of energy requirement, LED efficiency was recalculated to operating temperatures at $60{ }^{\circ} \mathrm{C}$ as stated in the datasheets.

\section{Results and discussion}

The ER of indoor plant production systems with exclusive LED lighting have not been reported so far. The cumulative ER per unit ground area with exclusive LED lighting is, according to our estimates, between 265 and $606 \mathrm{kWh}$ for a growth cycle of 100 days and $2500 \mathrm{~g}$ DW production (Table 3). The calculated ER can be used for dimensioning energy supply systems required to power LED lighting fields of indoor plant production units like those intensively investigated in the context of controlled environment life support systems (Bugbee 1992) and vertical farming concepts (see "Introduction"). In this paper, we want to elucidate the connection between light supply by technical means and the production of biomass. Plenty of articles on vertical farming exist in the market of scientific literature. In our opinion, most of them lack specific information on the processes we discuss in our paper and are by trend more visionary. Here, we want to make a contribution that this changes in the future. Comparable calculations and estimations of light 
and energy supply for biomass production was presented by Pattison et al. (2018). However, this paper addresses the topic on a more economical approach and the model applied is by nature parametric, while our approach focuses on the mechanistic of the photosynthetic stoichiometry. Further, our method also catches the dynamics of the quantum demand over time. For the estimation of the economic feasibility of plant production under artificial lighting, the parametric model is absolutely sound and, with solid estimations available for the given parameters, maybe even more reliable than our model. However, our approach is rendered unique by consequently connecting electric efficiency with a mechanistic model of the stoichiometry of photosynthesis and the back-calculation of quantum demand for plant growth over time.

The pronounced differences in ER between the two scenario calculations indicate that, by a combination of management practices such as $\mathrm{CO}_{2}$ enrichment and use of reflective materials, substantial energy savings can be achieved. The peak daily ER were 9.44 and $4.14 \mathrm{kWh} \mathrm{m}^{-2}$ in the PA and OA scenarios, respectively, and were substantially lower at the beginning and end of the growth cycle (Fig. 1). This highly dynamic ER during the growth cycle suggests that LED lighting fields should be designed to meet this variable and plant growth stage-specific energy supply. This could be a significant contribution to energy saving in greenhouses and indoor plant growth systems and could be achieved by either dimming the LED light field or by moving plants into a demand-defined light environment supplied by LED panels in separate sectors of the indoor growth facility. This could further include the option of supplying spectrally different light composition and, by that, exploiting ontogenetic-specific photo-morphogenetic effects.

A theoretical maximum energy conversion efficiency of photosynthetically active light $(400-740 \mathrm{~nm})$ at the plant surface of C3 plants of 9.5\% (Zhu et al. 2008; Amthor 2010) has been derived from consideration of biophysical and biochemical principles of $\mathrm{CO}_{2}$ assimilation. Relating the timeintegrated energy accumulation of the scenario crop to the electric energy demand, the energy conversion efficiencies in the PA and OA scenarios were 2.07 and $4.72 \%$. These values are unavoidably lower than the theoretical maximum energy conversion efficiency due to the energy losses along the physical transformation of electricity to quanta. LEDs vary in efficiency of plant-available Watt per Watt of electricity

Table 2 Peak wavelength $\left(\lambda_{\text {peak }}\right)$, efficiency (W plant available per $\mathrm{W}$ of electricity) and photon conversion efficiency of electricity to quanta $\left(\mathrm{CO}_{\text {Eff }}, 400-700 \mathrm{~nm}\right)$ of five different commercially available LEDs

\begin{tabular}{llll}
\hline Visible color & $\begin{array}{l}\lambda_{\text {peak }} \\
\mathrm{nm}\end{array}$ & $\begin{array}{l}\text { Efficiency } \\
\mathrm{W} \mathrm{W} \mathrm{W}^{-1}\end{array}$ & $\begin{array}{l}\mathrm{CO}_{\text {Eff }} \\
\mu \mathrm{mol} \mathrm{J}\end{array}$ \\
\hline Hyper red & 660 & 0.46 & 2.55 \\
Blue & 470 & 0.57 & 2.18 \\
Deep blue & 451 & 0.50 & 1.89 \\
True green & 521 & 0.18 & 0.78 \\
Cool white & $445 / 555$ & 0.28 & 1.35 \\
Hyper red:blue (5:1) & $470 / 660$ & 0.48 & 2.47 \\
HPS (SON-T, 400 W) & n.a. & 0.29 & 1.53 \\
\hline
\end{tabular}

LEDs at typical test conditions (forward current: $350 \mathrm{~mA}$, temperature: $25^{\circ} \mathrm{C}$ ), a combination of deep red and deep blue and a High Pressure Sodium lamp (SON-T, $400 \mathrm{~W}$ )
Fig. 1 Temporal dynamics of dry mass formation (DW, $\mathrm{g} \mathrm{m}^{-2}$; solid grey line), and energy requirements [ER, $\mathrm{kWh}$ $\left(\mathrm{m}^{2} \text { ground }\right)^{-1} \mathrm{day}^{-1}$ ] of the fictional plant stand. ER were calculated with the optimistic (OA, solid black line) and pessimistic (PA, broken line) approach as outlined in Table 1

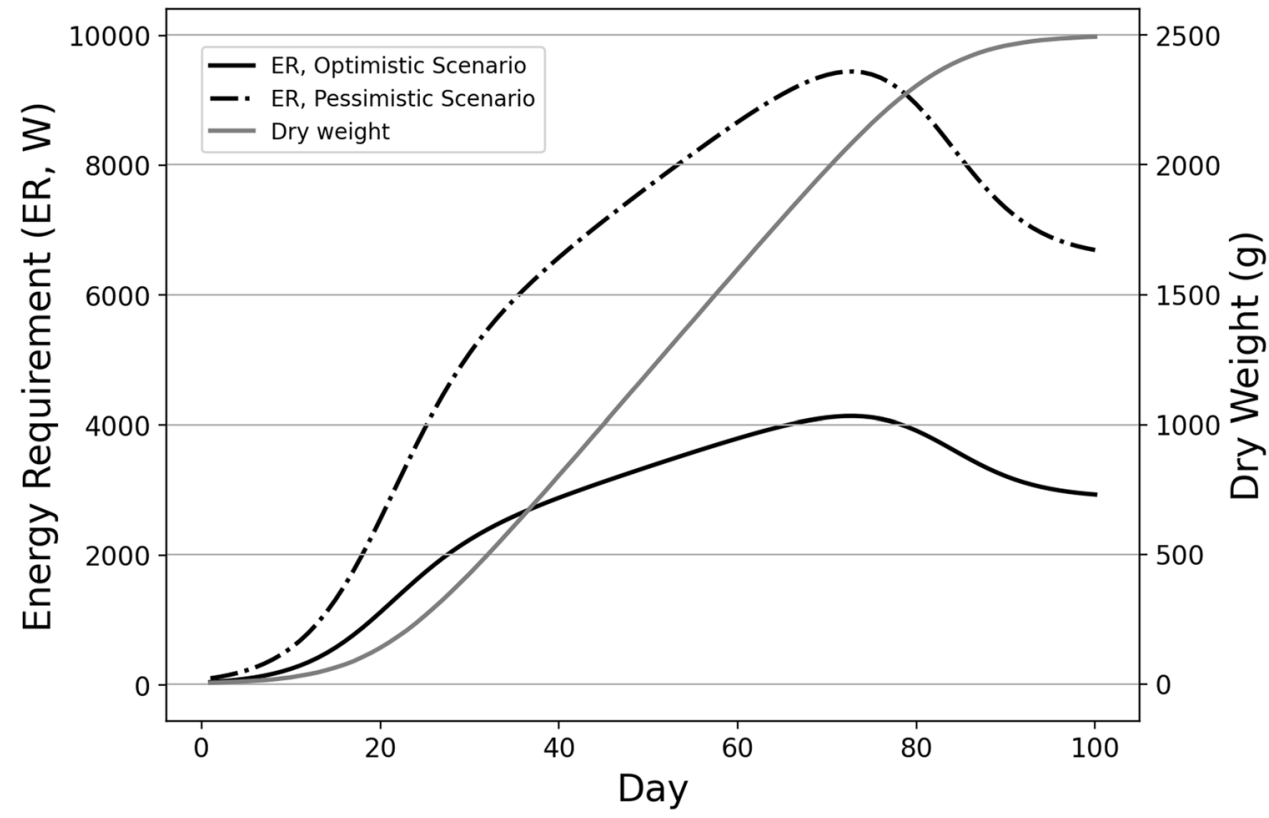




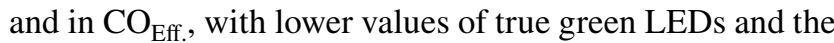
highest in deep red and blue LEDs (Table 2).

As indicated by differences in ER of the PA and OA scenarios by varying $\mathrm{f}_{\mathrm{abs}}$ and the ratio of carboxylation to oxygenation $(\Phi)$, technical options are relevant for energy savings. High $\mathrm{CO}_{2}$ environments are commercially used in order to suppress photorespiration. By reducing $\Phi$ from 0.28 to 0.05 , the ER was reduced from 606 to $437 \mathrm{kWh} \mathrm{m}^{-2}$ and $\varepsilon$ increased by $38 \%$ (Fig. 2). Although high $\mathrm{CO}_{2}$ environments appear as a feasible option for reducing energy costs and water requirements, the role of photorespiration in stress tolerance (Bauwe et al. 2010) and putative effects of $\mathrm{CO}_{2}$ enrichment on nutrient uptake and assimilation, and grain composition and quality (Fangmeier et al. 1999; Erda et al. 2005) must be considered in an integrated management approach.

The absorption of light by the plant canopy $\left(f_{a b s}\right)$ is relevant for the system's ER as an increase of $\mathrm{f}_{\mathrm{abs}}$ from 0.70 to 0.95 increased $\varepsilon$ by $24 \%$ (Fig. 2). As summarized in
Amthor (2010), dense canopies might absorb 90-95\% of photosynthetic active radiation (PAR), but so called inactive PAR absorption by pigments not involved in photosynthetic carbon assimilation may reduce the effective absorption to a certain, yet not well quantified, extent. A value of 0.95 in the OA scenario would imply that all quanta emitted by LEDs were absorbed by leaves and that only $5 \%$ of quanta were lost by conversion to heat and fluorescence. In order to minimize unproductive losses of light in greenhouses or indoor factories, plant density should be adjustable over the growth period to maximize canopy cover during the growth period. Secondly, the use of highly reflective surfaces surrounding plants can minimize losses by reflectance of plant canopies and increase the fraction of diffuse light. As shown by Tubiello et al. (1997), high levels of diffuse light can RUE by equalizing the high and low radiation levels at the upper and lower layers of the canopy, respectively. However, given that newer findings by Brodersen et al. (2008) suggest an increase of leaf level

Fig. 2 The energy conversion efficiencies $(\varepsilon)$ of a fictional plant stand producing $2500 \mathrm{~g}$ total DW $\mathrm{m}^{-2}$ during a growth cycle of 100 days. Calculations are based on the pessimistic approach (PA), and stepwise changes in parameters listed in Table 1 under the optimistic approach (OA), or with all parameters changed according to the OA scenario (a, b: quantum requirements, $\Phi$ : the ratio of oxygenation to carboxylation, $\mathrm{f}_{\mathrm{abs}}$ : the fraction of light absorbed by leaves)

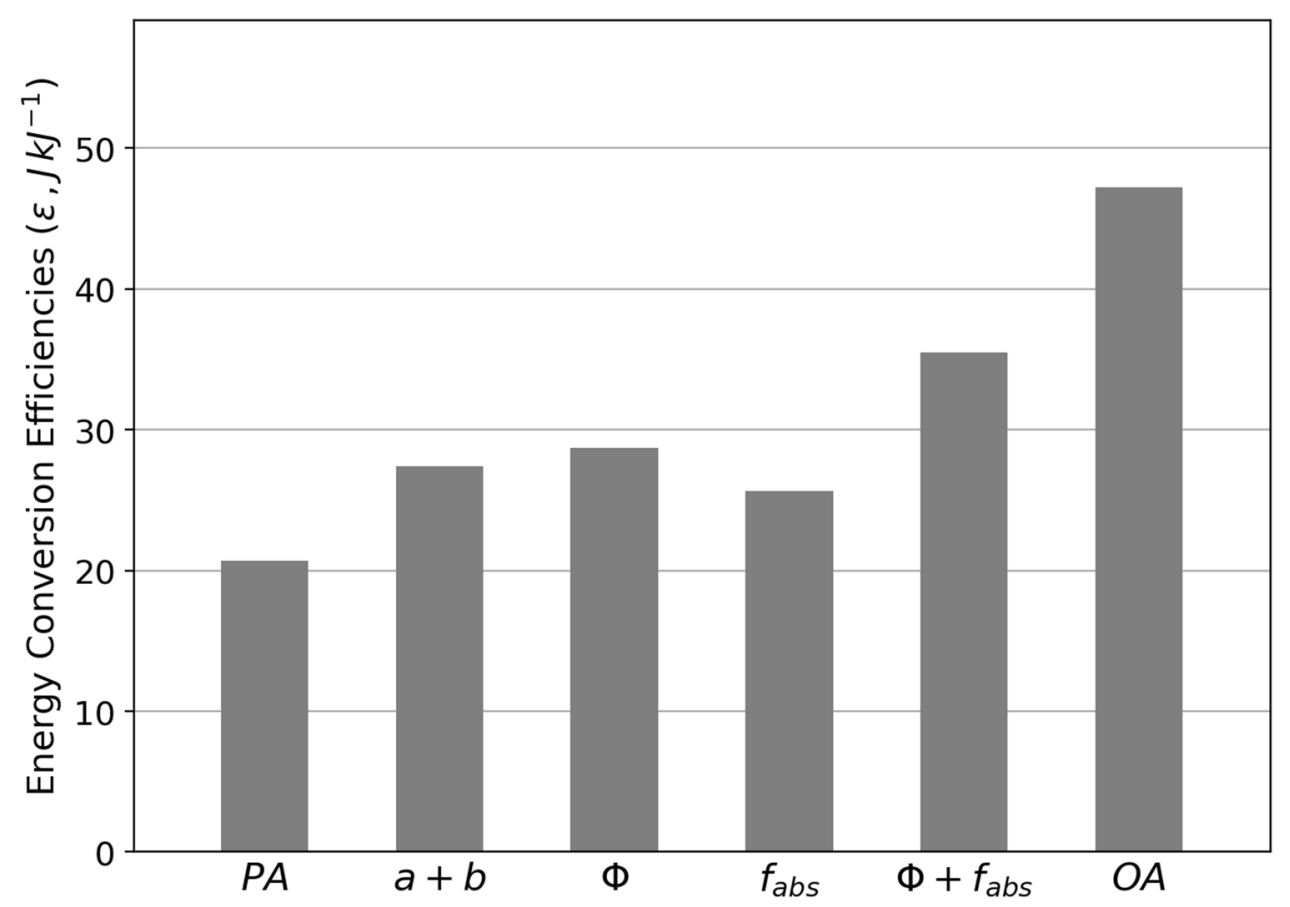

Table 3 Cumulative energy requirement (ER) for a dry weight formation of $2500 \mathrm{~g} \mathrm{~m}^{-2}$ during a crop growth cycle of 100 days for plants growing in an indoor system under a the PA/OA scenarios as described in Table 1

\begin{tabular}{lllllll}
\hline ER & PA & $\mathrm{a}+\mathrm{b}$ & $\Phi$ & $\mathrm{f}_{\mathrm{abs}}$ & & $\Phi+\mathrm{f}_{\text {abs }}$ \\
\hline $\mathrm{kWh} \mathrm{m}^{-2}$ & 606 & 458 & 437 & 489 & 353 & 265
\end{tabular}

Calculations were based on $\mathrm{CO}_{\mathrm{Eff}}$ of the a combination of deep red and blue LEDs with a red:blue photon ratio of 5:1 (Osram Opto Semiconductors $\mathrm{GmbH} \& \mathrm{Co}$., Regensburg, Germany) (see Table 2)

$a, b$ quantum requirements, $\Phi$ the ratio of oxygenation to carboxylation, $f_{a b s}$ the fraction of light absorbed by leaves 
photosynthesis under high direct light levels compared to equal irradiances of diffuse light for high light grown leaves, it seems plausible to focus on the development of an integrated lighting environment with respect to both the position of the light sources as well as to the light-directional quality. Technically, all the management options are feasible (Table 3).

Temperature control is one of the major items of energy balance sheets in greenhouse and indoor plant factory management and has not been assessed in our calculations. Calculated energy requirements cannot be considered as a fixed value under variable environmental temperatures since, due to temperature effects on solubility of gases, high temperature environments will increase the quantum requirements by higher rates of photorespiration [see Amthor (2010) for details]. Although technical aspects of temperature control and related energy costs are not considered here, the relevance is not at all questioned.

Additionally, to technical options for minimizing ER, some bio-physical processes of plant growth are highly relevant to improve estimates of real ER. Firstly, the quantum requirement is under debate as electron transport in the light reaction part of photosynthesis is apparently not simply a linear transport but has a constitutive or facultative operation of cyclic electron flow. Furthermore, the costs of ATP synthesis are not clear but transport of four $\mathrm{H}^{+}$through the chloroplastic ATP synthase may be required per ATP with up to $12 \mathrm{H}^{+}$transported into the thylakoid lumen per 8 quanta absorbed (Sacksteder et al. 2000; Amthor 2010). In our PA and OA scenarios, 15.78 and 11.94 quanta per rate of carboxylation would be required, estimates which are higher (PA) or comparable (OA) to the estimates used by Amthor (2010). Clarification of the quanta/ATP stoichiometry is not only of scientific interest but affects the QR and thus ER for LED based lighting systems. ER would decrease from 606 (PA) to $458 \mathrm{kWh} \mathrm{m}^{-2}$ if proton costs for ATP synthesis were lower than assumed in the PA scenario. In line with Sacksteder et al. (2000), we assume in our calculations, that energy demand during photosynthesis is defined by the ATP demand. By this we explicitly exclude the possibility of ATP import into the chloroplasts during the light phase and assume that the surplus of reducing equivalents is exported to the cytosol via the malate/oxalacetate shuttle (Scheibe 2004).

Maintenance respiration is a significant component of the plant's carbon economy and conceptually reflects all carbon costs related to ensure functionality of cells in terms of membrane potentials, $\mathrm{pH}$ regulation, de-toxification, and repair and turnover of structure and enzymes. Though clear in a biological sense, estimates of carbon costs of maintenance are methodologically difficult but are roughly of similar cumulative glucose requirements than those invested in growth respiration over a complete growth cycle (Loomis and Amthor 1999). In consideration of the functions supported by maintenance respiration, costs are evidently not constant per unit plant DW but expected to increase in stressful environments, with increasing $\mathrm{N}$ content of tissue and towards maturity. Relevance of maintenance respiration in our calculations is indicated by the peak energy demand at 73 days after sowing, while peak growth rate occurred at 52 days after sowing. This is due to the increasing relevance of maintenance respiration with plant age, keeping the ER at 100 days after sowing at high values. We likely overestimate cumulative ER in both scenarios as senescence of plant tissue and re-translocation from vegetative organs to grain will reduce ER during the generative growth phase.

\section{Conclusions}

The calculation of ER as outlined can be applied to any crop once the growth dynamics and energy content of plant organs is known, which often is the case. Unlike other lighting systems, LEDs are easily dimmable and can therefore be adjusted to the plants' demand which could substantially reduce energy costs. For example, we can see dimmable LEDs in a greenhouse to supply supplementary light to the natural one, if by season or cloud conditions, the QR (calculated from a model as outlined here in principle) is not sufficient. The basic approach of our calculations is valid for any vertical farming concept and already existing greenhouses. Relevance of our findings is highest for concepts of completely self-contained growth environments, since in traditional greenhouses the energy demand for thermal control is more relevant than energy requirements for lighting. Logically, hybrid systems with transitory supply of light through transparent surfaces will reduce the energy estimates of our study. With a more consolidated understanding of energy demand and conversion efficiency by plants, the construction of appropriate LED-based light fields should be possible. However, and as indicated by our consideration of pessimistic and optimistic approaches, the design of environmental conditions in sealed systems is far from trivial and plants are transferred into a combination of bio-physical factors (e.g., permanent light and high $\mathrm{CO}_{2}$ ) for which information is sparse in terms of presently used mechanistic plant growth models.

Acknowledgements Evaluation of and comments on our energy demand calculations of LED's by Janick Ihringer from OSRAM Opto Semiconductors GmbH, Regensburg, Germany, are gratefully acknowledged. 
Funding Open Access funding enabled and organized by Projekt DEAL.

Open Access This article is licensed under a Creative Commons Attribution 4.0 International License, which permits use, sharing, adaptation, distribution and reproduction in any medium or format, as long as you give appropriate credit to the original author(s) and the source, provide a link to the Creative Commons licence, and indicate if changes were made. The images or other third party material in this article are included in the article's Creative Commons licence, unless indicated otherwise in a credit line to the material. If material is not included in the article's Creative Commons licence and your intended use is not permitted by statutory regulation or exceeds the permitted use, you will need to obtain permission directly from the copyright holder. To view a copy of this licence, visit http://creativecommons.org/licenses/by/4.0/.

\section{References}

Alexandratos N, Bruinsma J (2003) World agriculture towards 2030/2050: the 2012 revision. ESA Working paper No. 12-03. FAO, Rome

Amthor JS (2010) From sunlight to phytomass: on the potential efficiency of converting solar radiation to phyto-energy. N Phytol 188:939-959. https://doi.org/10.1111/j.1469-8137.2010.03505.x

Balmford A, Bruner A, Cooper P et al (2002) Economic reasons for conserving wild nature. Science 297:950-953. https://doi. org/10.1126/science.1073947

Bauwe H, Hagemann M, Fernie AR (2010) Photorespiration: players, partners and origin. Trends Plant Sci 15:330-336

Beacham AM, Vickers LH, Monaghan JM (2019) Vertical farming: a summary of approaches to growing skywards. J Hortic Sci Biotechnol 94:277-283

Brodersen CR, Vogelmann TC, Williams WE, Gorton HL (2008) A new paradigm in leaf-level photosynthesis: direct and diffuse lights are not equal. Plant Cell Environ 31:159-164. https://doi. org/10.1111/j.1365-3040.2007.01751.x

Bugbee B (1992) Determining the potential productivity of food crops in controlled environments. Adv Space Res 12:85-95. https://doi. org/10.1016/0273-1177(92)90014-O

Bula RJ, Morrow RC, Tibbitts TW et al (1991) Light-emitting diodes as a radiation source for plants. HortScience 26:203-205

Cohen JE (1997) Population, economics, environment and culture: an introduction to human carrying capacity. J Appl Ecol 34:13251333. https://doi.org/10.2307/2405250

Cordell D, Drangert J, White S (2009) The story of phosphorus: global food security and food for thought. Glob Environ Chang 19:292-305

Despommier D (2011) The vertical farm: controlled environment agriculture carried out in tall buildings would create greater food safety and security for large urban populations. J Verbrauch Lebensm 6:233-236. https://doi.org/10.1007/s00003-010-0654-3

Erda L, Wei X, Hui J et al (2005) Climate change impacts on crop yield and quality with $\mathrm{CO}_{2}$ fertilization in China. Philos Trans R Soc B Biol Sci 360:2149-2154. https://doi.org/10.1098/rstb.2005.1743

Evans JR, Poorter H (2001) Photosynthetic acclimation of plants to growth irradiance: the relative importance of specific leaf area and nitrogen partitioning in maximizing carbon gain. Plant Cell Environ 24:755-767. https://doi.org/10.1046/j.1365-3040.2001.00724 .X

Falkenmark M, Kijne JW, Taron B et al (1997) Meeting water requirements of an expanding world population. Philos Trans Biol Sci 352:929-936. https://doi.org/10.2307/56536
Fangmeier A, De Temmerman L, Mortensen L et al (1999) Effects on nutrients and on grain quality in spring wheat crops grown under elevated $\mathrm{CO} 2$ concentrations and stress conditions in the European, multiple-site experiment "ESPACE-wheat". Eur J Agron 10:215-229. https://doi.org/10.1016/S1161-0301(99)00012-X

Folta KM, Koss LL, McMorrow R et al (2005) Design and fabrication of adjustable red-green-blue LED light arrays for plant research. BMC Plant Biol 5:1-11. https://doi.org/10.1186/1471-2229-5-17

Germer J, Sauerborn J, Asch F et al (2011) Skyfarming an ecological innovation to enhance global food security. J Verbrauch Lebensm 6:237-251. https://doi.org/10.1007/s00003-011-0691-6

Gilbert N (2009) The disappearing nutrient. Nature 461:716-718

Griffin KL (1994) Calorimetric estimates of construction cost and their use in ecological studies. Funct Ecol 8:551-562. https://doi. org/10.2307/2389915

Haenel H-D, Rösemann C, Dämmgen U, et al (2020) Calculations of gaseous and particulate emissions from German agriculture 1990-2018 Report on methods and data (RMD) Submission 2020 Berechnung von gas-und partikelförmigen Emissionen aus der deutschen Landwirtschaft 1990-2018 Report zu Methoden und Daten

Haitz R, Tsao JY (2011) Solid-state lighting: 'the case' 10 years after and future prospects. Phys Status Solidi 208:17-29. https://doi. org/10.1002/pssa.201026349

Jørgensen JR, Deleuran LC, Wollenweber B (2007) Prospects of whole grain crops of wheat, rye and triticale under different fertilizer regimes for energy production. Biomass Bioenerg 31:308-317. https://doi.org/10.1016/j.biombioe.2007.01.001

Kitinoja L, Saran S, Roy SK, Kader AA (2011) Postharvest technology for developing countries: challenges and opportunities in research, outreach and advocacy. J Sci Food Agric 91:597-603. https://doi. org/10.1002/jsfa.4295

Lambers H, Poorter H (1992) Inherent variation in growth rate between higher plants: a search for physiological causes and ecological consequences. In: Advances in ecological research, pp 187-261

Lobell DB, Burke MB, Tebaldi C et al (2008) Prioritizing climate change adaptation needs for food security in 2030. Science 319:607-610. https://doi.org/10.1126/science.1152339

Loomis RS, Amthor JS (1999) Yield potential, plant assimilatory capacity, and metabolic efficiencies. Crop Sci 39:1584-1596. https ://doi.org/10.1074/jbc.M908890199

Massa GD, Kim HH, Wheeler RM, Mitchell CA (2008) Plant productivity in response to LED lighting. HortScience 43:1951-1956

Morrow R (2008) LED lighting in horticulture. HortScience 43:1947-1950

OECD/IEA (2011) World energy outlook 2011. International Energy Agency, Paris

Pattison PM, Tsao JY, Brainard GC, Bugbee B (2018) LEDs for photons, physiology and food. Nature 563:493-500. https://doi. org/10.1038/s41586-018-0706-x

Sacksteder CA, Kanazawa A, Jacoby ME, Kramer DM (2000) The proton to electron stoichiometry of steady-state photosynthesis in living plants: a proton-pumping Q cycle is continuously engaged. Proc Natl Acad Sci USA 97:14283-14288. https://doi. org/10.1073/pnas.97.26.14283

Scheibe R (2004) Malate valves to balance cellular energy supply. Physiol Plant 120:21-26. https://doi.org/10.1111/j.0031-9317.2004.0222.x

Shamshiri RR, Kalantari F, Ting KC et al (2018) Advances in greenhouse automation and controlled environment agriculture: a transition to plant factories and urban agriculture. Int J Agric Biol Eng 11:1-22. https://doi.org/10.25165/j.ijabe.20181101.3210

Song XP, Tan HTW, Tan PY (2018) Assessment of light adequacy for vertical farming in a tropical city. Urban For Urban Green 29:49-57. https://doi.org/10.1016/j.ufug.2017.11.004

Tilman D, Balzer C, Hill J, Befort BL (2011) Global food demand and the sustainable intensification of agriculture. Proc Natl Acad Sci 108:20260-20264. https://doi.org/10.1073/pnas.1116437108 
Tubiello F, Volk T, Bugbee B (1997) Diffuse light and wheat radiationuse efficiency in a controlled environment. Life Support Biosph Sci 4:77-85

United Nations (2019) Selected results of the 2019 UN world population projections. Popul Dev Rev 45:689-694. https://doi. org/10.1111/padr.12288

von Caemmerer S, Farquhar GD (1981) Some relationships between the biochemistry of photosynthesis and the gas exchange of leaves. Planta 153:376-387. https://doi.org/10.1007/BF00384257

Walsh J (1991) The greening of the green revolution. Science 80(252):26. https://doi.org/10.1126/science.252.5002.26

Yin X, Goudriaan J, Lantinga EA et al (2003) A flexible sigmoid function of determinate growth. Ann Bot 91:361-371. https://doi. org/10.1093/aob/mcg029
Zabel P, Bamsey M, Schubert D, Tajmar M (2016) Review and analysis of over 40 years of space plant growth systems. Life Sci Sp Res 10:1-16. https://doi.org/10.1016/j.1ssr.2016.06.004

Zhu X-G, Long SP, Ort DR (2008) What is the maximum efficiency with which photosynthesis can convert solar energy into biomass? Curr Opin Biotechnol 19:153-159. https://doi.org/10.1016/j.copbi o.2008.02.004

Publisher's Note Springer Nature remains neutral with regard to jurisdictional claims in published maps and institutional affiliations. 